\title{
MODEL HIDRODINAMIKA BIOREAKTOR TANAMAN : KONSEP PERMEABILITAS
}

\author{
Mubiar Purwasasmita*) dan Khairul Hadi \\ Program Studi Teknik Kimia, Fakultas Teknologi Industri, Institut Teknologi Bandung \\ Jalan Ganesha 10 Bandung, 40132 \\ ${ }^{*}$ Penulis korespondensi : mubiar@che.itb.ac.id
}

\begin{abstract}
HYDRODYNAMIC MODEL OF THE PLANT BIOREACTOR (THE PERMEABILITY CONCEPT). Water flow is important in transport of plant nutrients. To accomadate water flow in plant bioreactor, it is necesary enough space by adding compost, i.e. material from plant residue which contains many of capillary tube. Many hydrodynamic models of water flow in porous and capillary medium are proposed, but there is no the specific model for plant bioreactor which contains particle beads and capillary tube. There are three models are proposed in this study, one each other are different in complexity. The first model has four parameters with mean error of 0.457 , the second one has five parameters with error of 0.464 , and the last one has seven parameters with mean error of 0.574. From the models, it is found that increasing in particle size or compost fraction will result in increasing permeability. With the compost to bed volume ratio of $1: 4$, the permeability increase significantly compared to the soil and sandstone. By taking into account of the permeability value in the governing equation of single cyllindrical root system, the water flow is not a rate limiting step for a long of the root. In order to ensure the existence of water flow in the bioreactor, it is suggested to use compost to bed volume ration of $1: 1$.
\end{abstract}

Keywords: flow in capillary-porous media; permeability; root water uptake; the plant bioreactor

\begin{abstract}
Abstrak
Aliran air dalam bioreaktor sangat penting dalam perpindahan nutrisi tanaman. Untuk memfasilitasi aliran air dalam bioreaktor tanaman, diperlukan rekayasa ruang melalui penambahan kompos, berupa material bekas tanaman yang mengandung pipa-pipa kapiler. Sudah tersedia berbagai model hidrodinamika untuk aliran lambat melewati unggun, namun belum ada yang secara khusus untuk bioreaktor tanaman yang memiliki butiran partikel dan potongan pipa kapiler. Pada kajian ini terdapat tiga model aliran yang ditinjau, masing-masing hanya berbeda dari sisi kompleksitasnya. Model pertama memiliki empat parameter dengan kesalahan rata-rata 0,457, model kedua memiliki lima parameter dengan kesalahan rata-rata 0,464, dan model ketiga dengan tujuh parameter dengan kesalahan rata-rata 0,574. Dengan menggunakan model tersebut diperoleh bahwa permeabilitas akan meningkat seiring dengan bertambahnya ukuran partikel dan atau fraksi kompos. Penambahan kompos seperempat dari volume unggun total akan memberikan peningkatan permeabilitas yang signifikan dibandingkan dengan tanah dan batuan pasir biasa. Dengan memasukkan parameter ini kedalam persamaan pengambilan air pada sistem akar silinder tunggal, maka perpindahan air bukan lagi menjadi tahap pembatas laju di sepanjang akar. Untuk menjamin ketersediaan aliran, disarankan menggunakan kompos sebesar setengah dari volume unggun total.
\end{abstract}

Kata kunci: aliran medium berpori-berkapiler; permeabilitas; pengambilan air oleh akar; bioreaktor tanaman

How to Cite This Article: Purwasasmita, M. dan Hadi, K., (2015), Model Hidrodinamika Bioreaktor Tanaman : Konsep Permeabilitas, Reaktor, 15(3), 154-164, http://dx.doi.org/10.14710/reaktor.15.3.154-164

\section{PENDAHULUAN}

Penelitian tentang bioreaktor tanaman berkembang pesat (Sharma dan Sharma, 2009; Abranches dkk., 2005). Perpindahan nutrisi dari dalam bioreaktor tanaman menuju akar dan seluruh bagian tanaman difasilitasi oleh aliran air. Apabila proses pengangkutan air di dalam bioreaktor menjadi tahap pembatas laju maka perpindahan nutrisi akan 
berlangsung lambat dan produktivitas tanaman tidak akan baik, meskipun ketersediaan sumber nutrisi tersebut dimediumnya tercukupi. Penambahan kompos kedalam bioreaktor akan memfasilitasi aliran air menuju rambut akar dengan mekanisme keterhubungan antar pipa dengan probabilitas tertentu. Integrasi ini akan menghilangkan hambatan perpindahan air dan dapat meningkatkan produktivitas tanaman, dan ini telah dibuktikan oleh sistem bercocok tanam SRI Organik Indonesia (Purwasasmita dan Sutaryat, 2012).

Bioreaktor tanaman merupakan medium yang terdiri dari potongan-potongan pipa dan butiranbutiran. Aliran utama yang masuk ke akar akan melewati potongan-potongan pipa, sedangkan aliran dari luar potongan pipa akan masuk kedalam pipa, yaitu berasal dari susunan butiran-butiran. Sistem perpipaan yang terputus-putus tersebut sangat berguna dalam mencegah adanya penyumbatan saluran oleh partikel-partikel yang lebih halus dari potonganpotongan pipa dalam medium, sehingga air dapat mengalir secara kontinyu. Sejauh ini belum ada yang membahas unggun dengan konsep seperti ini.

Aliran pada bioreaktor tanaman tersebut sejatinya merupakan aliran di medium berporiberkapiler. Medium seperti ini memiliki tipe bermacam-macam, namun memiliki model empiris dasar yaitu persamaan Darcy. Karena konfigurasi unggun yang kompleks, maka sulit untuk memperoleh persamaan umum untuk konstanta Darcy (permeabilitas). Persamaan yang ditemukan diliteratur hanya merepresentasikan medium yang dicobakan pada saat itu saja, antara lain Kozeny-Carman (KC) untuk unggun butiran bola (1937), Bish (1957) memberikan persamaan $\mathrm{KC}$ termodifikasi, $\mathrm{Yu}$ dan Chen (2000) untuk unggun dari rajutan benang. Dalam menganalisisnya pun para peneliti tersebut menggunakan pandangan yang berbeda-beda, seperti analisis geometri fraktal (Yu dkk, 2000) dan teori $\pi$ Buckingham (Kareem, 2008).

Berdasarkan mekanisme aliran bioreaktor tanaman, maka jumlah pipa (kompos) di dalamnya menjadi parameter penting. Hal ini sebanding dengan jumlah penambahan kompos. Makalah ini membahas tentang model hidrodinamika pada bioreaktor tanaman. Model yang dikembangkan dapat digunakan untuk menentukan jumlah kompos yang sesuai untuk bioreaktor tanaman.

\section{METODE PENELITIAN}

Penelitian dimulai dengan membangun model yang menggambarkan pengaruh perubahan tekanan total unggun terhadap laju alir per luas penampang unggun, dimana kedua variabel tersebut terhubung oleh konstanta permeabilitas atau konduktivitas unggun. Kajian difokuskan pada pendefinisian persamaan untuk permeabilitas. Permeabilitas ditentukan oleh harga parameter terukur yaitu porositas, fraksi kompos dan pasir, ukuran partikel kompos dan pasir, tinggi unggun dan diameter kolom unggun, dan beberapa parameter empirik yang ditentukan melalui pencocokan dengan data-data percobaan.

Percobaan dimulai dengan mengeringkan kompos dan pasir, kemudian menyeragamkan ukurannya (penentuan diameter rata-rata partikel) dengan menggunakan saringan mesh, setelah itu menentukan harga porositas total unggun melalui perbandingan volum. Prosedur aliran menggunakan rangkaian alat yang terdiri dari dua buah kolom seperti yang ditunjukkan pada Gambar 1. Uji aliran dilakukan untuk masing-masing unggun dengan komponen pasir yang lolos di saringan mesh no. 8 dan tidak no. 14 mesh (8/14), 14/18, 20/30, 30/35, dan 40/45, dan untuk kompos pada 8/14, 14/18, 20/30, dan 40/45. Perbandingan kompos dan pasir (K:P) adalah 0:1, 1:0, $1: 1,1: 1,4,1: 3,1: 5,2: 1$ dan 3:1. Masing-masing kondisi percobaan dilakukan secara diplo.

Pada saat uji aliran berlangsung data yang diambil adalah waktu terukur terhadap ketinggian air yang berubah pada kolom pertama (Gambar 1), data tersebut akan diolah dengan menggunakan Persamaan 1, sebagai berikut,

$$
\ln \left(\frac{\mathrm{h}_{0}}{\mathrm{~h}}\right)=\mathrm{a} \cdot \mathrm{t}
$$

Dimana,

$$
\mathrm{a}=\frac{\mathrm{B} \rho \mathrm{g}}{2 \mu\left(\mathrm{L}_{\mathrm{U}}+\mathrm{I}\right)}\left(1+\left[\frac{\mathrm{R}_{1}}{\mathrm{R}_{2}}\right]^{2}\right)
$$

Persamaan 1 dan 2 diperoleh dari analisis neraca makro air pada rangkaian alat yang tersaji pada Gambar 1.

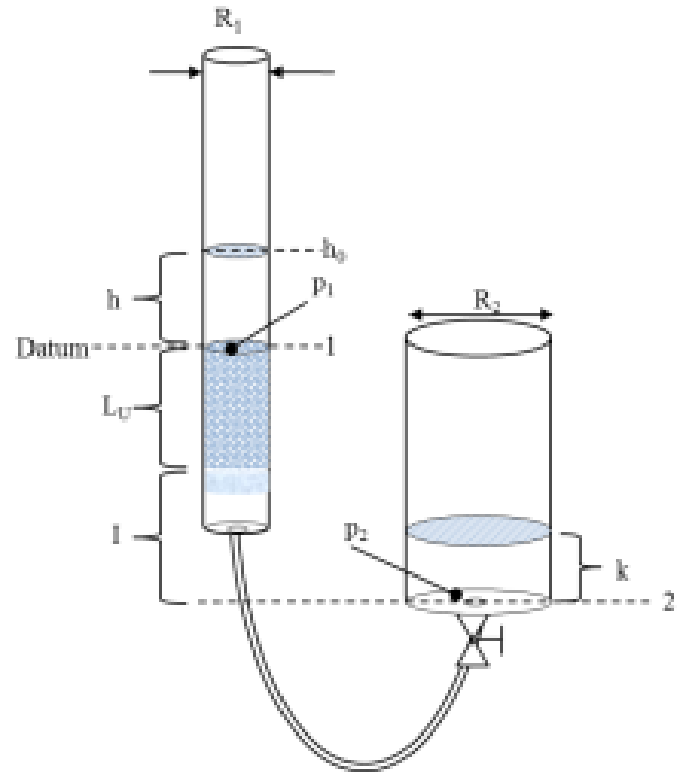

Gambar 1. Rangkaian alat yang digunakan, aliran air mengalir dari kolom 1 ke kolom 2 , dimana $\mathrm{R}_{1}=2,9$

$$
\mathrm{cm}, \mathrm{R}_{2}=4,7 \mathrm{~cm}, \mathrm{~L}_{\mathrm{u}}=10 \mathrm{~cm}, \mathrm{I}=15,5 \mathrm{~cm}
$$

Setelah uji aliran selesai, jumlah air yang terperangkap pada unggun dihitung berdasarkan jumlah volum awal dengan volum akhir atau yang 
tersisa. Hal ini bertujuan untuk mengidentifikasi porositas eksternal dari unggun. Porositas eksternal adalah fraksi rongga-rongga diluar pipa kapiler terhadap total unggun.

Harga permeabilitas B yang telah diperoleh dicocokkan dengan model yang telah dibangun untuk menentukan parameter-parameter empirik yang ada pada model tersebut dengan menggunakan Solver pada Ms. Excell. Setelah persamaan diperoleh, melakukan pemodelan pengambilan air oleh akar dengan melibatkan permeabilitas yang telah dihitung dengan menggunakan persamaan aliran di bioreaktor tanaman. Persamaan pengambilan air oleh akar memberikan gambaran mengenai distribusi tekanan hidrostatik disepanjang akar untuk sistem akar berupa silinder tunggal.

\section{HASIL DAN PEMBAHASAN Pengembangan Model}

Model dikembangkan menggunakan asumsi yaitu fluida yang mengalir di dalamnya adalah air padatemperatur kamar dan tekanan sekitar adalah atmosferik.Pola aliran diasumsikan pada dua rejim yaitu aliran yang melewati potongan-potongan pipa homogen, dan aliran yang melewati butiran homogen (Gambar 2a dan b), konfigurasi butiran dan unggun terdiri dari dua jenis yaitu konfigurasi maksimum yang terdiri dari empat butiran (Gambar 2c dan d) dan konfigurasi minimum yang terdiri dari tiga butiran (Gambar 2e dan f) serta kondisi unggun dianggap kaku.

Jika laju alir massa yang melewati pipa 1 adalah $\mathrm{W}_{1}$, maka jumlah laju alir massa di pipa 2 didefinisikan sebagai jumlah aliran dari pipa 1 ditambah dengan aliran dari butiran (luar pipa) dikurangkan dengan jumlah aliran di pipa 1 yang keluar pipa, hal ini dapat ditulis sebagai berikut,

$$
\mathrm{W}_{2}=\mathrm{W}_{1}\left(1-\xi_{1}\right)+\mathrm{W}_{1}
$$

Dimana $\xi$ adalah fraksi cairan yang keluar dari pipa menuju butiran terhadap yang mengalir di pipa yang bersangkutan, dan $\mathrm{W}$ adalah jumlah laju alir massa di luar pipa (butiran) yang masuk ke pipa. Untuk pipa ke 3 dan ke $\mathrm{N}$ dapat dituliskan dalam bentuk aliran pipa 1 sebagaimana persamaan di atas, maka diperoleh,

$$
\begin{aligned}
\mathrm{W}_{3}= & \mathrm{W}_{1}\left(1-\xi_{1}\left(1-\xi_{2}\right)-\xi_{2}\right)+\mathrm{W}_{1}\left(1-\xi_{2}\right)+\mathrm{W}_{2} \\
\mathrm{~W}_{\mathrm{N}}= & \mathrm{W}_{1}\left(1-\xi_{1}\left(1-\ldots-\xi_{\mathrm{N}-2}\left(1-\xi_{\mathrm{N}-1}\right)\right)-\xi_{\mathrm{N}-1}\right)+ \\
& \mathrm{W}_{1}\left(1-\xi_{2}\left(1-\ldots-\xi_{\mathrm{N}-2}\left(1-\xi_{\mathrm{N}-1}\right)\right)-\xi_{\mathrm{N}-1}\right)+ \\
& +\ldots+\mathrm{W}_{\mathrm{N}-2}\left(1-\xi_{\mathrm{N}-1}\right)+\mathrm{W}_{\mathrm{N}-1}
\end{aligned}
$$

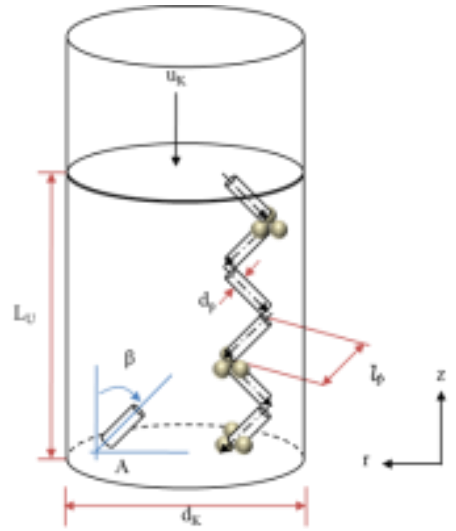

(a)

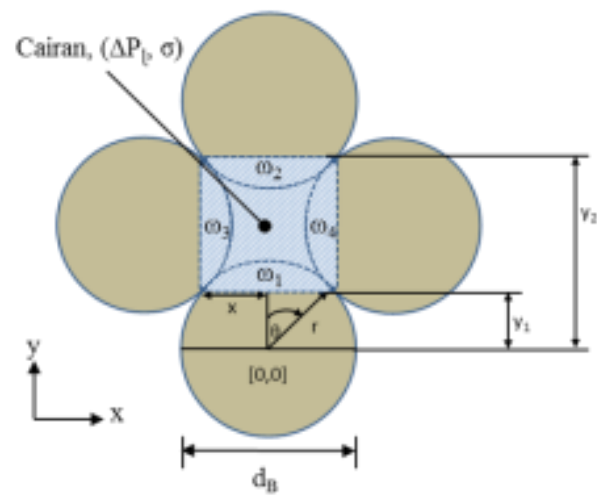

(d)

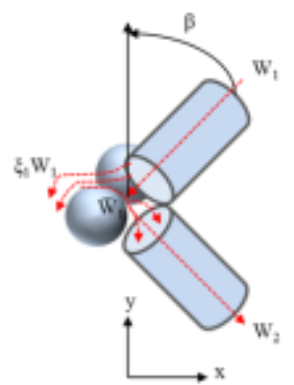

(b)

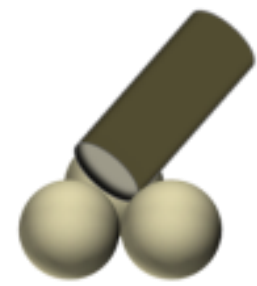

(e)

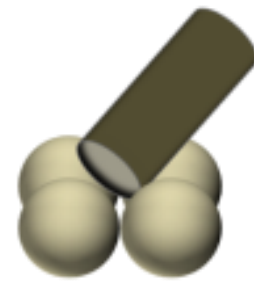

(c)

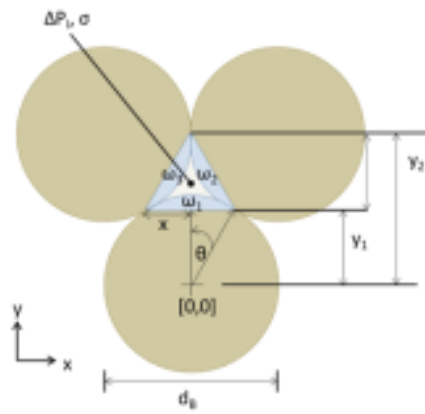

(f)

Gambar 2. Mekanisme aliran di dalam unggun (a dan b) dan dua jenis konfigurasi dengan butiran pasir untuk satu unit sel (c dan d) pori butiran maksimum dan (e dan $\mathrm{f}$ ) pori butiran minimum. 

yaitu,

Dan jumlah aliran total, $\mathrm{W}_{\text {tot }}$ di dalam unggun

$$
\mathrm{W}_{\text {tot }}=\mathrm{W}_{1}+\mathrm{W}_{2}+\mathrm{W}_{3}+\ldots+\mathrm{W}_{\mathrm{N}}
$$

Karena harga $\xi$ dan $\mathrm{W}$ untuk masing-masing pipa sulit ditentukan maka dilakukan penyederhanaan, sebagai berikut,

$$
\begin{gathered}
\xi_{1}=\xi_{2}=\xi_{3}=\ldots=\xi_{\mathrm{N}-1}=\xi, \text { dan } \mathrm{W}_{1}=\mathrm{W}_{2}=\mathrm{W}_{3} \\
=\ldots=\mathrm{W}_{\mathrm{N}}=\mathrm{W}
\end{gathered}
$$

Berdasarkan Persamaan 4, 5 dan 7, maka Persamaan 6 dapat dituliskan lagi sebagai berikut,

$$
\begin{aligned}
\mathrm{W}_{\text {tot }}= & \mathrm{W}_{1}\left(\alpha_{1,1}+\alpha_{1,2}+\alpha_{1,3}+\alpha_{1,4}+\ldots+\alpha_{1, \mathrm{~N}}\right) \\
& +\mathrm{W}\left(\alpha_{2,2}+\alpha_{2,3}+\alpha_{2,4}+\ldots+\alpha_{2, \mathrm{~N}}\right)
\end{aligned}
$$

Dimana $\alpha_{1, i}$ adalah parameter ukuran aliran yang lewat di potongan pipa ke-i, dan $\alpha_{2, i+1}$ adalah parameter ukuran aliran yang lewat dari ruang kosong antar butiran dipipa i masuk ke potongan pipa ke$i+1$.Harga $\alpha_{1,1}$ hingga $\alpha_{1, \mathrm{~N}}$ dan $\alpha_{2,2}$ hingga $\alpha_{2, \mathrm{~N}}$ yang berbeda-beda ditiap tahap sangat sulit untuk ditentukan bahkan untuk kondisi yang benar-benar seragam sekalipun, sehingga dilakukan penyederhanaan kembali yaitu,

$$
\mathrm{W}_{\text {tot }}=\mathrm{W}_{1} \bar{\alpha}_{1}+\mathrm{W} \bar{\alpha}_{2}
$$

Dengan, $\bar{\alpha}_{1}=\alpha_{1,1}+\alpha_{1,2}+\alpha_{1,3}+\alpha_{1,4}+\ldots+\alpha_{1, \mathrm{~N}}$ dan $\bar{\alpha}_{2}=$ $\alpha_{2,2}+\alpha_{2,3}+\alpha_{2,4}+\ldots+\alpha_{2, \mathrm{~N}} \cdot \bar{\alpha}_{1}$, dan $\bar{\alpha}_{2}>0$.

Kedua ruas pada Persamaan 9 dibagi dengan densitas cairan, $\rho$, sehingga menjadi persamaan laju alir volumetrik $Q_{\text {tot }}$, yakni,

$$
\mathrm{Q}_{\text {tot }}=\mathrm{q}_{1} \bar{\alpha}_{1}+\mathrm{q}_{2} \bar{\alpha}_{2}, \mathrm{q}_{2}=\mathrm{W} / \mathrm{\rho}
$$

Dimana, $\mathrm{Q}_{\text {tot }}=\mathrm{U}_{\mathrm{tot}} \cdot \mathrm{A}, \mathrm{q}_{1}=\mathrm{U}_{1} \cdot \mathrm{A}_{\mathrm{p}} \mathrm{dan} \mathrm{q}_{2}$ merupakan laju alir yang masuk melalui porositas eksternal pada butiran-butiran yang diwakilkan oleh banyaknya fraksi pori eksternal (diluar pipa, $\varepsilon_{X}$ ) di dalam unggun dikali dengan laju alir total, $\mathrm{q}_{2}=\varepsilon_{X}$. $\mathrm{Q}_{\text {tot. }}$ Aliran pada satu potong pipa dianalisis dengan menggunakan neraca momentum sehingga diperoleh.

$$
\begin{gathered}
\mathrm{U}_{1}=\frac{\mathrm{r}^{2}-\mathrm{R}_{\mathrm{p}}{ }^{2}}{4 \mu}\left[\frac{\Delta \mathrm{p}}{\mathrm{l}_{\mathrm{p}}}+\rho \mathrm{g} \cos \beta\right] \\
\mathrm{U}_{1}=\frac{\Delta \mathrm{P}_{\mathrm{p}}}{\mathrm{l}_{\mathrm{p}} 4 \mu}\left(\mathrm{r}^{2}-\mathrm{R}_{\mathrm{p}}{ }^{2}\right)
\end{gathered}
$$

Dengan mengintegrasikan di luas permukaan pipa maka diperoleh laju alir volumetrik $\mathrm{q}_{1}$.

$$
\mathrm{U}_{1} \mathrm{~A}_{1}=-\frac{\Delta \mathrm{P}_{\mathrm{p}}}{1_{\mathrm{p}} 8 \mu} \pi \mathrm{R}_{\mathrm{P}}^{4}
$$

Dengan melakukan pendekatan bahwa harga hilang tekan di satu partikel pipa perdimensi panjang pipa merupakan fungsi dari porositas total $(\varepsilon)$ dan fraksi total partikel pipa $\left(f_{p}\right)$ di dalam unggun dikali dengan hilang tekan kolom perdimensi panjang kolom, maka dihipotesiskan bahwa,

$$
\frac{\Delta \mathrm{P}_{\mathrm{p}}}{\mathrm{l}_{\mathrm{p}}}=\left(\varepsilon^{\mathrm{n}}+\mathrm{f}_{\mathrm{p}}^{\mathrm{m}}\right) \frac{\Delta \mathrm{P}}{\mathrm{L}_{\mathrm{U}}}
$$

Dimana $\mathrm{n}$ dan $\mathrm{m}$ adalah parameter yang harus ditentukan dari data, dan $\mathrm{f}_{\mathrm{p}}$ merupakan fraksi total partikel pipa (kompos), yaitu perbandingan antara fraksi padat di dalam unggun dibagi dengan fraksi kompos di dalam padatan, sehingga diperoleh,

$$
\mathrm{f}_{\mathrm{p}}=\frac{1-\varepsilon_{X}}{1+(1 / \mathrm{a})}
$$

Dimana a adalah perbandingan antara kompos dan pasir yang ada di unggun, dan $\varepsilon_{X}$ diperoleh dari harga porositas total dikurangi dengan jumlah hold up cairan di unggun setelah uji aliran. Dengan memasukkan Persamaan 12, 13, dan 14 ke Persamaan 10 maka diperoleh model pertama yaitu,

$$
\mathrm{U}_{\text {tot }}=-\frac{\left(\varepsilon^{\mathrm{n}}+\mathrm{f}_{\mathrm{p}}{ }^{\mathrm{m}}\right) \alpha_{1}}{\left(1-\varepsilon_{\mathrm{X}}{ }^{\alpha_{2}}\right)}\left(\frac{\mathrm{R}_{\mathrm{p}}}{\mathrm{R}_{\mathrm{K}}}\right)^{2} \frac{\Delta \mathrm{P}}{8 \mu \mathrm{L}_{\mathrm{U}}}
$$

Selain ditentukan melalui percobaan, $\varepsilon_{X}$ juga dihitung dengan pendekatan sebagai berikut $\varepsilon_{X}=\eta \varepsilon$, dimana $\eta$ fraksi porositas eksternal terhadap porositas total, dengan nilai $0<\eta<1$, dan ini ditentukan secara empirik dari data percobaan. Dengan mendefenisikan hal tersebut pada Persamaan 15 maka diperoleh model kedua yaitu,

$$
\mathrm{U}_{\text {tot }}=-\frac{\left(\varepsilon^{\mathrm{n}}+\left[\frac{1-\eta \varepsilon}{1+1 / \mathrm{a}}\right]^{\mathrm{m}}\right) \alpha_{1}}{\left(1-\eta \varepsilon \alpha_{2}\right)}\left(\frac{\mathrm{R}_{\mathrm{p}}}{\mathrm{R}_{\mathrm{K}}}\right)^{2} \frac{\Delta \mathrm{P}}{8 \mu \mathrm{L}_{\mathrm{U}}}
$$

Pendekatan berikutnya dalam menentukan $\varepsilon_{X}$ yakni dengan menurunkan volum rongga eksternal secara teoritis sehingga $\varepsilon_{\mathrm{X}}=\mathrm{V}_{\mathrm{ex}} / \mathrm{V}_{\mathrm{U}}$, dimana volum rongga eksternal $\left(\mathrm{V}_{\mathrm{ex}}\right)$ ditentukan dengan menggunakan konfigurasi butiran yang diasumsikan berdasarkan Gambar. 2d dan f, dengan definisi sebagai berikut,

$$
\mathrm{V}_{\mathrm{ex}}=\mathrm{N}\left(\beta_{1} \mathrm{~V}_{1, \mathrm{I}}+\left(1-\beta_{1}\right) \mathrm{V}_{1, \mathrm{II}}\right)
$$

Dimana $\mathrm{N}$ adalah jumlah total unit rongga eksternal di dalam unggun, $\beta_{1}\left(0<\beta_{1}<1\right)$ adalah fraksi rongga untuk satu unit volum dengan konfigurasi maksimum, $\mathrm{V}_{1, \mathrm{I}}$ volum satu unit rongga sel dengan konfigurasi maksimum, dan $\mathrm{V}_{1, \mathrm{II}}$ adalah volum satu unit rongga sel dengan konfigurasi minimum. Metode penurunan yang digunakan merujuk pada Heris dkk. (2009), yang menurunkan untuk kondisi dua butiran berbeda ukuran, namun disini kondisi tersebut diekspansi untuk 4 butiran (konfigurasi maksimum), dan 3 butiran (konfigurasi minimum) yang seragam.

\section{Konfigurasi Maksimum}

Jumlah volum cairan yang berada di dalam rongga diantara butiran dipengaruhi beda tekan antara cairan dan lingkungannya $\Delta \mathrm{P}_{\mathrm{l}}$, tegangan permukaan $\sigma$ dan luas permukaan butiran yang ditutupi oleh butiran $\omega$. Untuk konfigurasi maksimum (Gambar 2d) dapat ditulis sebagai berikut,

$$
\Delta \mathbf{P}_{\ell}=\sigma\left(\frac{1}{\omega_{1}}+\frac{1}{\omega_{2}}+\frac{1}{\omega_{3}}+\frac{1}{\omega_{4}}\right)
$$

Untuk suatu silinder simetris, diperlukan suatu persamaan garis dimana, jika dirotasikan akan 
memberikan luas antarmuka. Berdasarkan Heris dkk. (2009), persamaan garis tersebut ialah sebagai berikut,

$$
\frac{1}{\omega}=\left(\frac{d^{2} y}{d x^{2}}\right) \frac{1}{\left(1+(d y / d x)^{2}\right)^{3 / 2}}
$$

Untuk butiran homogen, maka $\omega_{1}=\omega_{2}=\omega_{3}=$ $\omega_{4}=\omega$, dengan mengenalkan variabel tak berdimensi $\mathrm{x}^{*}=\mathrm{x} / \mathrm{R}_{\mathrm{B}}, \quad \mathrm{y}^{*}=\mathrm{y} / \mathrm{R}_{\mathrm{B}}$, dan memasukkan Per. 19 kedalam 18, maka diperoleh,

$$
\gamma=\mathrm{Y}^{\prime \prime} \frac{1}{\left(1+\mathrm{Y}^{2}\right)^{3 / 2}}, \gamma=\frac{\Delta \mathrm{P}_{\ell} \mathrm{R}_{\mathrm{B}}}{4 \sigma}, \mathrm{Y}^{\prime}=\frac{\mathrm{dy}^{*}}{\mathrm{dx} \mathrm{x}^{*}}, \mathrm{Y}^{\prime \prime}=\frac{\mathrm{d}^{2} \mathrm{y}^{*}}{\mathrm{dx} \mathrm{x}^{2}}
$$

Pada setiap butiran dapat didefinisikan beberapa terminasi berikut.

$\mathrm{X}^{*}=\mathrm{x} / \mathrm{R}_{\mathrm{B}}=\sin \theta, \alpha=\mathrm{Y}^{\prime}=(\tan \theta)^{-1}, \mathrm{Y}^{\prime \prime}=\alpha \mathrm{d} \alpha / \mathrm{dy} \mathrm{y}^{*}(21)$

Dengan memasukkan terminasi pada Persamaan 21 kedalam Persamaan 20 dan untuk kenyamanan penulisan * dihilangkan, maka akan diperoleh,

$$
\gamma=\alpha \frac{\mathrm{d} \alpha}{\mathrm{dy}} \frac{1}{\left(1+\alpha^{2}\right)^{3 / 2}}
$$
menjadi,

Persamaan di atas kemudian diintegrasikan

$$
-\left(1+\alpha^{2}\right)^{-0,5}=\gamma \mathrm{y}+\mathrm{C}_{\mathrm{i}}
$$

Dengan kondisi batas bahwa pada saat $\mathrm{y}=\mathrm{y}_{1}=\mathrm{y}_{1} / \mathrm{r}$, maka $\alpha_{1}=\left(\tan \theta_{1}\right)^{-1},\left(1+\alpha_{1}^{2}\right)^{-0,5}=1 / \sin \theta_{1}=$ $1 / \sin \theta$ dan Persamaan 23 dapat ditulis lagi menjadi,

$$
\alpha=\frac{d y}{d x}=\left(\frac{1}{\left(1 / \sin \theta-\gamma\left(y-y_{1}\right)\right)^{2}}-1\right)^{0,5}
$$

Persamaan diatas kemudian diintegrasi dengan batas, $\mathrm{x}_{1}$ hingga $\mathrm{x}$, dan $\mathrm{y}_{1}$ hingga $\mathrm{y}_{2}$, dimana $\mathrm{x}_{1}=\sin \theta_{1}$ dan untuk butiran seragam $\sin \theta_{1}=\sin \theta \approx 0,725, \cos \theta$ $\approx 0,677, \tan \theta \approx 1,071$, dan $\mathrm{y}_{2}=3.4 \mathrm{y}_{1}$ maka diperoleh,

$$
\mathrm{x}=\frac{[(0.975 / \gamma)-0.670]}{0.687 \gamma-1}\left(-3.158 \gamma^{2}+2.749 \gamma-0.933\right)^{0.5}+0,725
$$

Persamaan di atas digunakan untuk menentukan volum putaran (total) dari Persamaan 19, dan volum cairan terdefinisi sebagai volum total dikurangi dengan volum padatan dari butiran yang ditutupi oleh cairan yaitu,

$$
\begin{aligned}
\frac{\mathrm{V}_{1, \mathrm{I}}}{\pi \mathrm{R}_{\mathrm{B}}{ }^{3}} & =-\left(1-\cos \theta_{1}\right) \frac{\left(2+\cos \theta_{1}-\cos ^{2} \theta_{1}\right)}{3} \\
& -\left(1-\cos \theta_{2}\right) \frac{\left(2+\cos \theta_{2}-\cos ^{2} \theta_{2}\right)}{3\left(\mathrm{R}_{\mathrm{B}, 1} / \mathrm{R}_{\mathrm{B}, 2}\right)^{3}} \\
& -\left(1-\cos \theta_{3}\right) \frac{\left(2+\cos \theta_{3}-\cos ^{2} \theta_{3}\right)}{3\left(\mathrm{R}_{\mathrm{B}, 1} / \mathrm{R}_{\mathrm{B}, 3}\right)^{3}} \\
& -\left(1-\cos \theta_{4}\right) \frac{\left(2+\cos \theta_{4}-\cos ^{2} \theta_{4}\right)}{3\left(\mathrm{R}_{\mathrm{B}, 1} / \mathrm{R}_{\mathrm{B}, 4}\right)^{3}} \\
& +\int_{\mathrm{y}_{1}}^{\mathrm{y}_{2}} \mathrm{x}^{2} \mathrm{dy}
\end{aligned}
$$

Karena butiran diasumsikan seragam maka Persamaan 26 dapat disederhanakan lagi menjadi,

$$
\frac{\mathrm{V}_{1, \mathrm{I}}}{\pi \mathrm{R}_{\mathrm{B}}{ }^{3}}=-\frac{4}{3}(1-\cos \theta)\left(2+\cos \theta-\cos ^{2} \theta\right)+\int_{\mathrm{y}_{1}}^{\mathrm{y}_{2}} \mathrm{x}^{2} \mathrm{dy}
$$

Dengan mendefinisikan $R_{B}$ sebagai $d_{B}$ yaitu diameter butiran, maka integrasi dari Persamaan 27 akan memberikan.

$$
\mathrm{V}_{1, \mathrm{I}}=\Gamma_{1} \pi \mathrm{d}_{\mathrm{B}}^{2}
$$

Dimana

$$
\begin{aligned}
\Gamma_{1} & =\frac{1.625 \Gamma^{2}+2.356 \Gamma-0.101}{8} \\
\Gamma & =\frac{[(0.975 / \gamma)-0.670]}{0.687 \gamma-1}\left(-3.158 \gamma^{2}+2.749 \gamma-0.933\right)^{0.5}
\end{aligned}
$$

\section{Konfigurasi Minimum}

Penyelesaian untuk konfigurasi minimum analog dengan sebelumnya, yaitu Persamaan 18 dapat ditulis ulang menjadi,

$$
\Delta \mathbf{P}_{\ell}=\sigma\left(\frac{1}{\omega_{1}}+\frac{1}{\omega_{2}}+\frac{1}{\omega_{3}}\right)
$$

Pada konfigurasi ini harga trigonometrinya yaitu $\mathrm{x}_{1}=\sin \theta_{1}=\sin \theta \approx 0.895, \mathrm{y}_{1}=\cos \theta \approx 0.446$, dantan $\theta \approx 2.009$, dan $\mathrm{y}_{2}=2 \mathrm{y}_{1}$, dengan menganalogikan sebagaimana halnya tabung dan kerucut, maka Persamaan 25-28, dapat ditulis lagi menjadi,

$$
\begin{aligned}
& \mathrm{x}=-\left(0.314 \gamma+\frac{1.264}{\gamma}\right)+0.895 \\
& \frac{\mathrm{V}_{1, \mathrm{II}}}{\pi \mathrm{R}_{\mathrm{B}}{ }^{3}}=--\frac{3}{3}(1-\cos \theta)\left(2+\cos \theta-\cos ^{2} \theta\right) \\
&+\frac{1}{3} \int_{\mathrm{y}_{1}}^{\mathrm{y}_{2}} \mathrm{x}^{2} \mathrm{dy} \\
& \mathrm{V}_{1, \mathrm{II}}=\Lambda_{1} \pi \mathrm{d}_{\mathrm{B}}{ }^{3}
\end{aligned}
$$


Dimana,

$\Lambda_{1}=\frac{0.149 \Lambda^{2}-0.267 \Lambda-1.126}{8}$,

$\Lambda=\left(0.314 \gamma+\frac{1.264}{\gamma}\right)$

Dengan demikian maka $\varepsilon_{\mathrm{X}}$ dapat ditulis ulang sebagai,

$$
\varepsilon_{\mathrm{X}}=4 \mathrm{~N}\left(\beta_{1} \Gamma_{1}+\left(1-\beta_{1}\right) \Lambda_{1}\right) \frac{\mathrm{d}_{\mathrm{B}}{ }^{3}}{\mathrm{~d}_{\mathrm{K}}{ }^{2} \mathrm{~L}_{\mathrm{U}}}
$$

Dengan pendekatan bahwa $\mathrm{N}$ adalah perbandingan antara volum unggun total dengan volum pori eksternal $\left(1 / \varepsilon_{\mathrm{X}}\right)$, maka Persamaan34 dapat ditulis lagi menjadi.

$$
\varepsilon_{\mathrm{X}}=\frac{2 \mathrm{~d}_{\mathrm{B}}}{\mathrm{d}_{\mathrm{K}}}\left[\left(\beta_{1} \Gamma_{1}+\left(1-\beta_{1}\right) \Lambda_{1}\right) \frac{\mathrm{d}_{\mathrm{B}}}{\mathrm{L}_{\mathrm{U}}}\right]^{0.5}
$$

Dengan memasukkan Persamaan 35 ke Persamaan 14 dan 15, maka diperoleh model ketiga yaitu Persamaan 36.

\section{Harga Permeabilitas}

Dengan menggunakan Persamaan 1 dan 2 pada data yang diperoleh, maka diperoleh harga permeabilitas untuk masing-masing kondisi yang dapat dilihat pada Tabel 1.

Dari harga tersebut terlihat bahwa semakin besar ukuran partikel butiran maka akan semakin besar permeabilitasnya, demikian pula semakin besar komposisi kompos yang ditambahkan maka akan semakin besar pula permeabilitas. Hal ini disebabkan semakin besar ukuran partikel maka ruang tidak ditempati secara efektif oleh padatan sehingga memperbesar porositas yang mengakibatkan semakin mudahnya air mengalir, demikian pula dengan semakin meningkatnya komposisi kompos maka heterogenitas medium juga bertambah, yang memberikan ruang lebih besar akibat susunan butiran dan pipa yang saling terganjal.

\section{Harga Parameter}

Nilai parameter empiris ditentukan dengan menggunakan aplikasi solver pada Ms.Excell, dimulai dari parameter milik model yang paling sederhana, kemudian harga dari model yang paling sederhana dijadikan sebagai tebakan awal untuk model berikutnya hingga model yang ketiga. Harga-harga parameter tersebut dapat dilihat pada Tabel 2 .

Tabel 1. Daftar harga permeabilitas yang diukur dari data percobaan.

\begin{tabular}{ccccc}
\hline $\begin{array}{c}\text { Kompos : } \\
\text { Pasir }\end{array}$ & $\begin{array}{c}\text { Diameter } \\
\text { rata-rata } \\
\text { pipa } \\
\text { (cm) }\end{array}$ & $\begin{array}{c}\text { Diameter } \\
\text { rata-rata } \\
\text { butiran } \\
(\mathrm{cm})\end{array}$ & $\varepsilon$ & $\begin{array}{c}\mathrm{B} .10^{6} \\
\left(\mathrm{~cm}^{2}\right)\end{array}$ \\
\hline $1: 3$ & 0,189 & 0,189 & 0,512 & 1,625 \\
$1: 1$ & 0,189 & 0,189 & 0,486 & 4,082 \\
$3: 1$ & 0,189 & 0,189 & 0,542 & 7,900 \\
$1: 1$ & 0,121 & 0,055 & 0,620 & 7,210 \\
$1: 1$ & 0,121 & 0,073 & 0,670 & 9,957 \\
$2: 1$ & 0,121 & 0,073 & 0,681 & 1,095 \\
$1: 5$ & 0,121 & 0,073 & 0,600 & 6,474 \\
$1: 1,4$ & 0,121 & 0,121 & 0,662 & 4,168 \\
$1: 1$ & 0,073 & 0,073 & 0,643 & 7,538 \\
$3: 1$ & 0,073 & 0,073 & 0,670 & 7,969 \\
$1: 1$ & 0,073 & 0,093 & 0,643 & 6,639 \\
$-: 1$ & - & 0,189 & 0,417 & 2,268 \\
$-: 1$ & - & 0,093 & 0,361 & 1,739 \\
$-: 1$ & - & 0,039 & 0,306 & 1,361 \\
$1:-$ & 0,093 & - & 0,472 & 19,995 \\
$1:-$ & 0,039 & - & 0,403 & 6,917 \\
\hline & & & &
\end{tabular}

Tabel 2. Harga parameter untuk masing-masing model

\begin{tabular}{cccc}
\hline \multirow{2}{*}{ Parameter } & $\begin{array}{c}\text { Model } \\
\text { Pertama }\end{array}$ & $\begin{array}{c}\text { Model } \\
\text { Kedua }\end{array}$ & $\begin{array}{c}\text { Model } \\
\text { Ketiga }\end{array}$ \\
\hline $\mathrm{n}$ & 8,173 & 8,288 & 5,065 \\
$\mathrm{~m}$ & 5,770 & 5,955 & 1,649 \\
$\alpha_{1}$ & 3,496 & 3,794 & 0,091 \\
$\alpha_{2} .10^{-4}$ & 1,267 & 1,267 & 1,001 \\
$\eta$ & - & 0,65 & - \\
$\beta_{1}$ & - & - & 0,353 \\
$\Gamma_{1}$ & - & - & 0,9067 \\
$\Lambda_{1}$ & - & - & 0,971 \\
Kesalahan & 0,457 & 0,464 & 0,574 \\
\hline
\end{tabular}

$$
\left.\left.\mathrm{U}_{\text {tot }}=-\frac{\left(\varepsilon^{\mathrm{n}}+\left[\frac{1-\left(\frac{2 \mathrm{~d}_{\mathrm{B}}}{\mathrm{d}_{\mathrm{K}}}\left[\left(\beta_{1} \Gamma_{1}+\left(1-\beta_{1}\right) \Lambda_{1}\right) \frac{\mathrm{d}_{\mathrm{B}}}{\mathrm{L}_{\mathrm{U}}}\right]^{0.5}\right)}{1+1 / \mathrm{a}}\right]^{\mathrm{m}}\right)}{\left(1-\left(\frac{2 \mathrm{~d}_{\mathrm{B}}}{\mathrm{d}_{\mathrm{K}}}\left[\left(\beta_{1} \Gamma_{1}+\left(1-\beta_{1}\right) \Lambda_{1}\right) \frac{\mathrm{d}_{\mathrm{B}}}{\mathrm{L}_{\mathrm{U}}}\right]^{0.5}\right) \alpha_{\mathrm{p}}\right.}\right)^{2} \frac{\Delta \mathrm{P}}{\mathrm{d}_{\mathrm{K}}}\right)^{\frac{\mathrm{d}_{2}}{8 \mu \mathrm{L}_{\mathrm{U}}}}
$$


Dari hasil yang diperoleh, terlihat bahwa $n>m$, dimana $\mathrm{n}$ dan $\mathrm{m}>1$, untuk semua model, hal ini menunjukkan porositas total memiliki pengaruh yang jauh lebih kecil dibandingkan keberadaan kompos, karena harga $\varepsilon$ dan $f_{p}$ antara 0 dan 1 , kondisi ini bersesuaian di lapangan yaitu untuk harga porositas yang sama medium yang ditambahkan dengan kompos lebih baik dengan tanpa kompos. Selain itu diperoleh juga bahwa $\eta$ dan $\beta_{1}$ berharga antara 0 hingga 1 dan ini rasional karena parameter tersebut adalah suatu harga fraksi, kesamaan harga yang diestimasi dan harga percobaan dapat dilihat pada Gambar 3 dan pada Gambar 4 diketahui hasil permeabilitas dihitung dengan model yang telah dibangun dan terlihat bahwa semakin besar porositas dan fraksi kompos maka semakin besar harga permeabilitasnya, yang bersesuaian dengan percobaan.

Berdasarkan bentuk modelnya, model pertama merupakan model yang paling sederhana, sedangkan ketiga adalah yang paling komplek, namun harga kesalahannya tidak berbanding lurus dengan kompleksitasnya. Hal ini kemungkinan karena terdapat parameter-parameter yang boleh jadi merupakan suatu variabel tidak tetap, seperti $\eta$ dan $\beta_{1}$, dimana harganya berubah berdasarkan komposisi kompos dan pasir yang digunakan. Demikian pula dengan variabel $\Gamma_{1}$ dan $\Lambda_{1}$, selain berubah terhadap komposisi, juga dipengaruhi oleh keseragaman aliran. Meskipun kekurangan ini teridentifikasi namun solusinya masih belum ditemukan karena variabelvariabel tersebut sangat sulit untuk diukur.

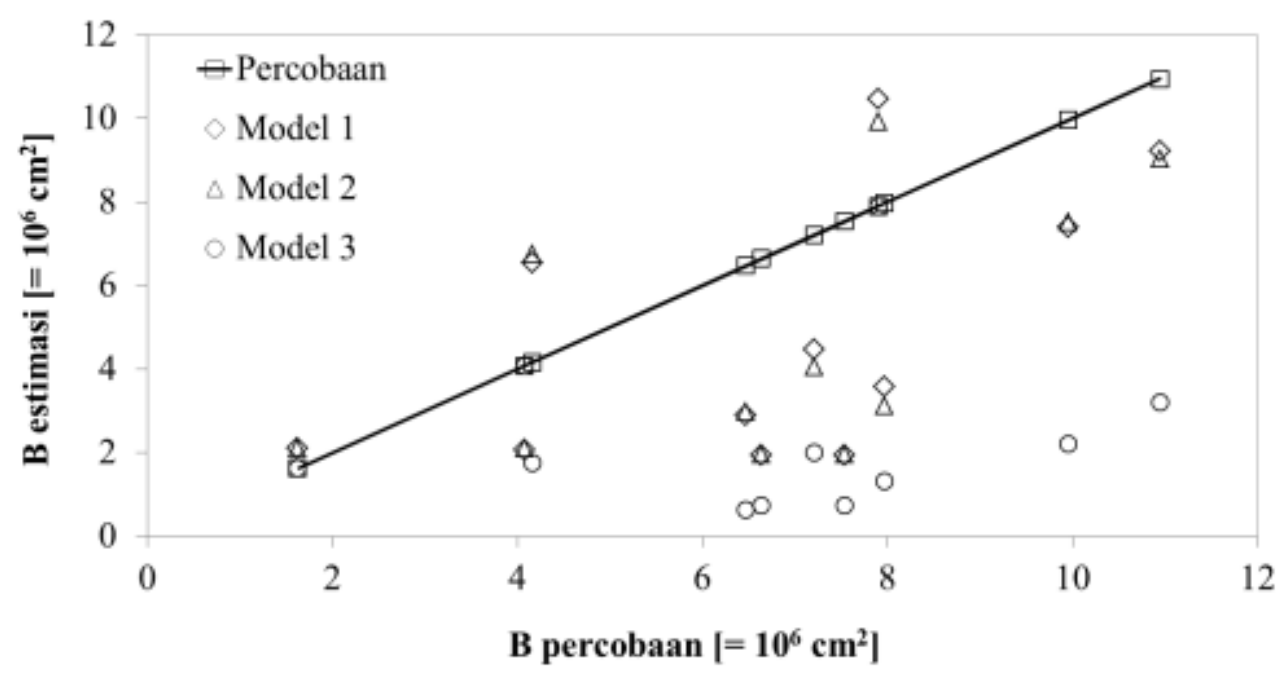

Gambar 3. Plot kesamaan harga permeabilitas terestimasi dengan harga permeabilitas terukur

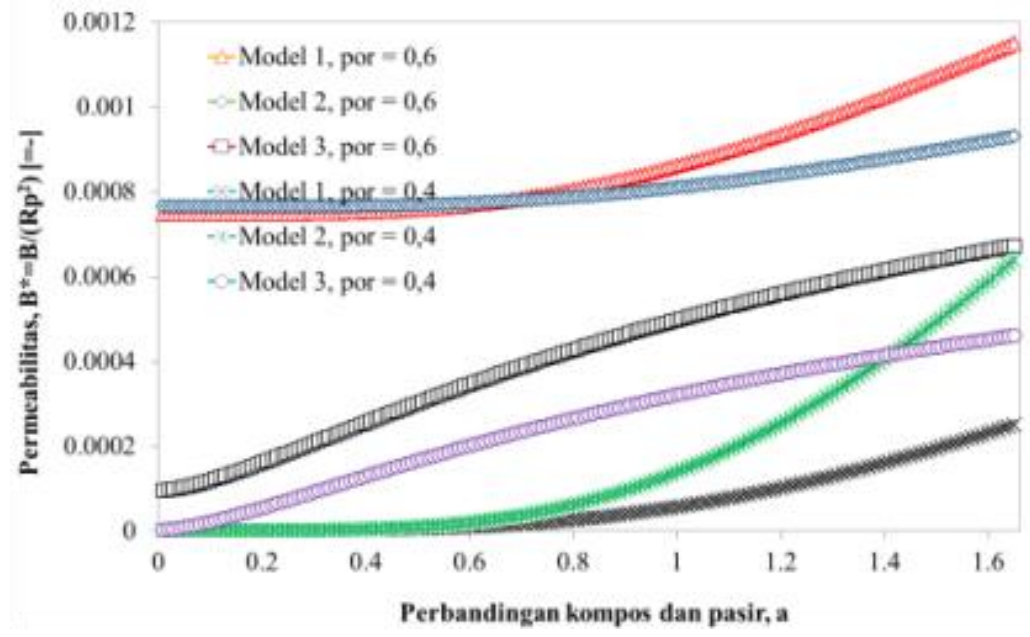

Gambar 4. Permeabilitas yang dihitung dengan Persamaan $\mathrm{B}=\mathrm{U}_{\text {tot }} \cdot \mu . \mathrm{L}_{\mathrm{U}} /(-\Delta \mathrm{P})$ dari Persamaan 15,16 dan 36. dengan $\mathrm{R}_{\mathrm{P}}=\mathrm{R}_{\mathrm{B}}=0,01 \mathrm{~cm}, \mathrm{R}_{\mathrm{K}}=3 \mathrm{~cm}, \mathrm{~L}_{\mathrm{U}}=10 \mathrm{~cm}$ dan $\varepsilon_{\mathrm{X}}=0,3$ 


\section{Estimasi Distribusi Tekanan Cairan di Bioreaktor}

Perhitungan ini dilakukan berdasarkan kondisi percobaan Persamaan Richard-Darcy (Richard, 1931), namun permeabilitas B akan dimodifikasi dengan model ketiga. Model ini dipilih karena memiliki variabel yang bergantung terhadap arah $\mathrm{z}$ dan $\mathrm{r}$ relatif terhadap bioreaktor tanaman secara keseluruhan, sehingga bisa disesuaikan dengan Persamaan RichardDarcy dalam hal menentukan turunan permeabilitas relatif terhadap arah radial dan arah aksial. Pada keadaan kontinyu persamaan-persamaan tersebut dapat ditulis ulang menjadi,

$$
\mathrm{B} \nabla^{2} \psi+\nabla \mathrm{B} \cdot \nabla \psi+\mathrm{g} \frac{\partial \mathrm{B}}{\partial \mathrm{z}}=0
$$

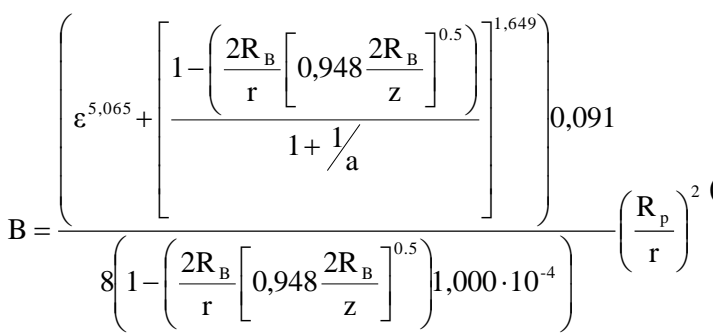

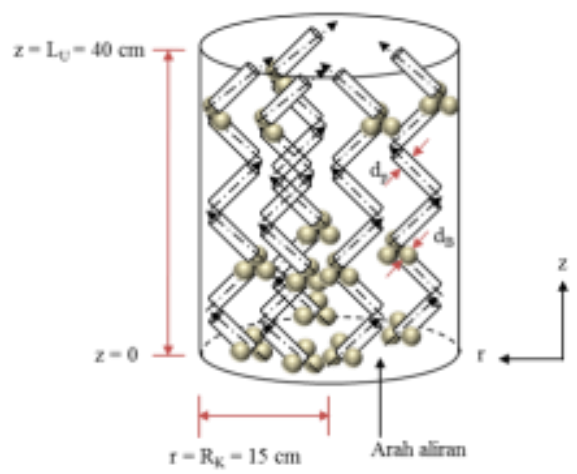

(a)
Persamaan tersebut diterapkan pada kondisi dimana dimensi bioreaktor tanaman berbentuk silinder, dengan tinggi (z) sebesar $40 \mathrm{~cm}$, dan jari-jari (r) $15 \mathrm{~cm}$ sebagaimana yang terlihat pada Gambar 5 .

Persamaan di atas memiliki kondisi batas saat $\mathrm{z}=0, \psi=$ harga potensial kapiler dasar (diasumsikan langsung bersentuhan dengan permuakaan air bebas sehingga harganya konstan), dengan menjadikan harga ini sebagai referensi maka $\psi=0 \mathrm{~cm}^{2} / \mathrm{s}^{2}$, pada saat di bagian tepi bioreaktor tanaman, $\mathrm{z}=\mathrm{L}_{\mathrm{U}}, \mathrm{r}=\mathrm{R}_{\mathrm{K}}$, maka $\mathrm{d} \psi / \mathrm{dz}$ dan $\mathrm{d} \psi / \mathrm{dr}=0$ yang berarti tidak mengalami perubahan lagi di setiap masing-masing arah. Dengan menggunakan FLexPDE v6.32 student version, maka diperoleh hasil yang dapat dilihat pada Gambar 6.

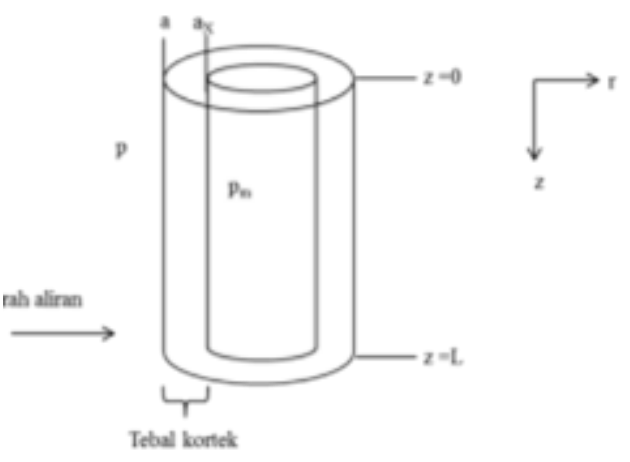

(b)

Gambar 5. Skema bioreaktor tanaman dengan mekanisme aliran kapiler yang terjadi di dalamnya(a) dan sistem akar sederhana berupa silinder tunggal (b).

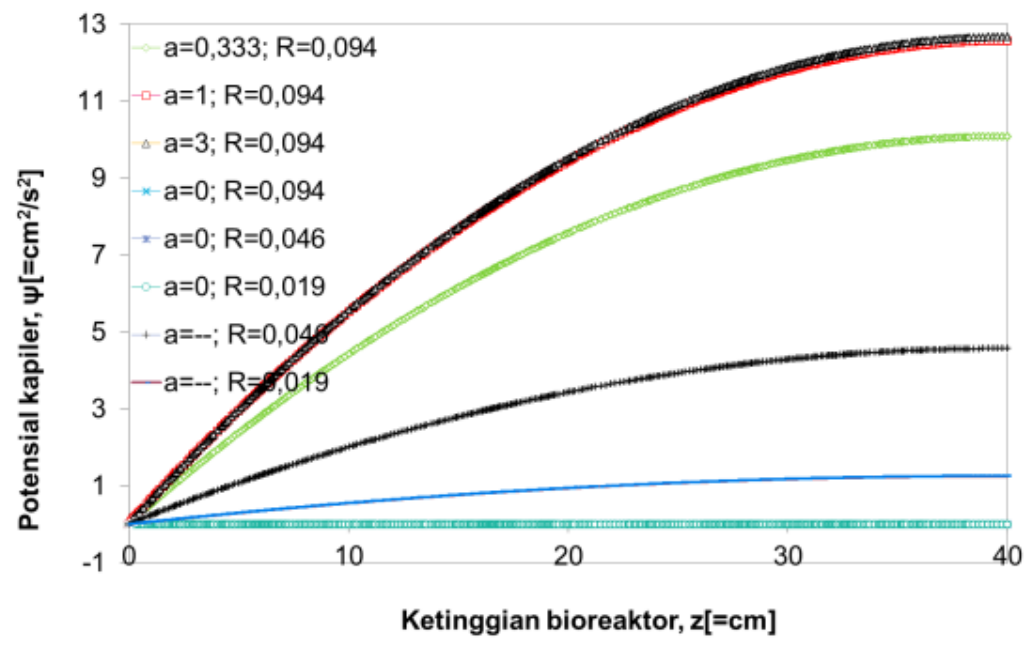

Gambar 6. Profil distribusi tekanan di dalam bioreaktor tanaman pada kondisi percobaan. 
Pada Gambar 6 terlihat bahwa terdapat peningkatan potensial kapiler sepanjang ketinggian bioreaktor, potensial kapiler tersebut diakibatkan oleh adanya aliran kapiler menuju keatas (pada aliran kapiler, jumlah potensial kapiler bergantung pada jumlah cairan kapiler), sehingga semakin besar potensial kapiler menunjukkan semakin banyak aliran kapiler menuju keatas. Pada gambar diatas jugadiperoleh informasi bahwa unggun yang terdiri variasi kompos dan pasir lebih baik dibandingkan dengan pasir saja $(a=0)$ atau kompos saja $(a=\infty)$.

Fenomena itu mungkin saja terjadi, karena dengan komposisi pasir dan kompos yang sesuai memberikan peluang lebih untuk terjadinya keterhubungan antara pipa satu dan lainnya di dalam unggun. Dengan demikian, perbandingan kompos:pasir diatas 1 tidak memberikan peningkatan yang signifikan terhadap aliran kapiler, sehingga kondisi ini merupakan kondisi optimum dimana aliran maksimum dapat dicapai di dalam bioreaktor tanaman.

\section{Estimasi Distribusi Tekanan Cairan Sepanjang} Akar

Pengaruh suatu permeabilitas dapat dilihat pada pengambilan air dari bioreaktor tanaman oleh akar, dengan mengasumsikan akar berbentuk silinder tunggal, kemudian menerapkan persamaan pembangun yang telah disusun oleh Molz (1981) kedalam koordinat silinder (Gambar 5b) maka diperoleh persamaan pembangun sebagai berikut,

$$
\frac{\partial \mathrm{p}_{\mathrm{m}}}{\partial \mathrm{t}}=\mathrm{D} \frac{1}{\mathrm{r}} \frac{\partial}{\partial \mathrm{r}}\left(\mathrm{r} \frac{\partial \mathrm{p}_{\mathrm{m}}}{\partial \mathrm{r}}\right)
$$

Dimana $\mathrm{p}_{\mathrm{m}}$ adalah tekanan terukur, dan Dadalah koefisien perpindahan yang merupakan fungsi permeabilitas dan viskositas. Kemudian langkah-langkah penurunan berikutnya merujuk kepada Roose (2000), yaitu memiliki kondisi batas saat $\mathrm{r}=\mathrm{a}$ (yaitu jari-jari) maka $\mathrm{p}_{\mathrm{m}}=\mathrm{p}$ (tekanan bioreaktor), dan pada saat $\mathrm{r}=\mathrm{a}_{\mathrm{X}}$ (dipermukaan kortek), maka $\mathrm{p}_{\mathrm{m}}=\mathrm{p}_{\mathrm{r}}$ (tekanan akar di xylem), kemudian mendekati Persamaan 39 untuk sistem kontinyu maka diperoleh persamaan akhir yaitu,

$$
\mathrm{p}_{\mathrm{m}}=\frac{\mathrm{p}-\mathrm{p}_{\mathrm{r}}}{\mathrm{a}-\mathrm{a}_{\mathrm{X}}} \mathrm{r}-\mathrm{a}+\mathrm{p}
$$

Besarnya laju alir volumetrik persatuan luas yang melewati permukaan akar dengan jari-jari $r=a$ adalah.

$$
\mathrm{D} \frac{\partial \mathrm{p}_{\mathrm{m}}}{\partial \mathrm{r}}=\frac{\mathrm{D}}{\mathrm{a}-\mathrm{a}_{\mathrm{X}}}\left(\mathrm{p}-\mathrm{p}_{\mathrm{r}}\right)
$$

Dalam makalahnya Roose (2000), secara tidak langsung menunjukkan bahwa D merupakan perbandingan antara konduktivitas tanah dengan viskositas air dan jumlah ini disebut sebagai konduktivitas radial $\left(\mathrm{k}_{\mathrm{r}}\right)$, dan perubahan tekanan terukur merujuk pada perubahan tekanan di dalam tanah, sehingga Persamaan 41 dapat ditulis kembali menjadi.

$$
\begin{aligned}
& \frac{\mathrm{B}}{\mu} \frac{\partial \mathrm{p}}{\partial \mathrm{r}}=\mathrm{k}_{\mathrm{r}}\left(\mathrm{p}-\mathrm{p}_{\mathrm{r}}\right), \text { pada } \mathrm{r}=\mathrm{a}, \\
& \text { dimana } \mathrm{k}_{\mathrm{r}}=\mathrm{B} /(\text { tebal kortex } . \mu)
\end{aligned}
$$

Dalam meninjau arah aliran vertikal pada pembuluh xylem di dalam akar, aliran dianggap terjadi di dalam pipa lurus dengan kecepatan rendah, sehingga untuk satu pembuluh xylem persamaan pembangunnya dapat didekati dengan menggunakan persamaan Poiseuille yaitu,

$$
\mathrm{q}^{*}=-\frac{\mathrm{R}_{\mathrm{X}}{ }^{4}}{8 \mu}\left(\frac{\partial \mathrm{p}_{\mathrm{r}}}{\partial \mathrm{z}}-\rho \mathrm{g}\right)
$$

Dimana $\mathrm{q}^{*}$ adalah laju volumetrik untuk satu pembuluh xylem. Jika terdapat sejumlah $\mathrm{n}$ pembuluh xylem, maka laju volumetrik total $\mathrm{q}^{*}$ tot adalah $\mathrm{nq}^{*}$, dan harga suku pengali diruas kanan dikalikan dengan n maka disebut sebagai konstanta konduktivitas aksial akar, sehingga Persamaan 43 dapat ditulis lagi menjadi,

$$
\mathrm{q}^{*}{ }_{\text {tot }}=-\mathrm{k}_{\mathrm{X}}\left(\frac{\partial \mathrm{p}_{\mathrm{r}}}{\partial \mathrm{z}}-\rho \mathrm{g}\right)
$$

Pada kondisi aliran setimbang, jumlah air yang masuk secara radial akan sama dengan jumlah air yang berpindah secara aksial di dalam pembuluh xylem, maka dengan menyamakan Persamaan 44 dengan 42, kemudian mendiferensiasikannya terhadap panjang akar (arah aksial) maka akan diperoleh persamaan berikut,

$$
-\mathrm{k}_{\mathrm{X}} \frac{\partial^{2} \mathrm{p}_{\mathrm{r}}}{\partial \mathrm{z}^{2}}=2 \pi \mathrm{a} \mathrm{k}_{\mathrm{r}}\left(\mathrm{p}-\mathrm{p}_{\mathrm{r}}\right)
$$

Dengan kondisi batas, pada $\mathrm{z}=0$ maka $\mathrm{p}_{\mathrm{r}}=\mathrm{T}$ (tekanan pangkal akar), dan $\mathrm{dp}_{\mathrm{r}} / \mathrm{dz}=0$ pada saat $\mathrm{z}=\mathrm{L}$, kemudian melakukan non-dimensionalisasi yaitu dengan, kemudian melakukan non-dimensionalisasi yaitu dengan,

$\mathrm{z}^{*}=\mathrm{z} / \mathrm{L}, \mathrm{p}_{\mathrm{r}}{ }^{*}=\mathrm{p}_{\mathrm{r}} / \mathrm{T}, \mathrm{P}_{0}=\mathrm{p} / \mathrm{T}=$ konstan $($ tekanan tanah) $(46)$

Memasukkan semua terminasi di Persamaan 46 kedalam Persamaan 45 lalu untuk kenyamanan penulisan, tanda * dihilangkan, maka diperoleh hasil yaitu,

$$
\begin{gathered}
\frac{1}{\kappa^{2}} \frac{d^{2} p_{r}}{d z^{2}}-p_{r}=-P_{0}, \\
\text { dimana } \kappa=L\left(2 \pi a \frac{k_{r}}{k_{x}}\right)^{0,5}
\end{gathered}
$$

Dengan kondisi batas pada $\mathrm{z}=0$, maka $\mathrm{p}_{\mathrm{r}}=1$, dan pada $\mathrm{z}=1$ maka $\mathrm{dp}_{\mathrm{r}} / \mathrm{dz}=0$, Persamaan akhir diatas diselesaikan dengan FlexPDE v6.32 student version, dengan kondisi-kondisi dan parameter yang diketahui merujuk pada disertasi Roose (2000). 


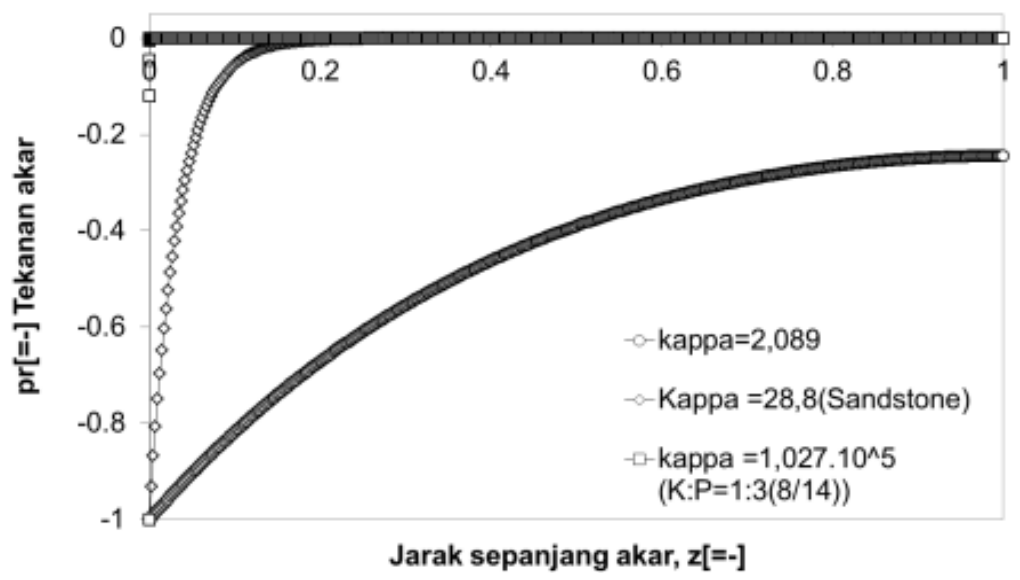

Gambar 7. Perbandingan harga tekanan hidrolik air disepanjang akar yang berada di berbagai medium, $\kappa=2.089$ (Roose 2000) (medium berupa tanah lempung), $\kappa=28.8$ (medium merupakan pasir-pasir batuan yang gersang), $\kappa=102684$ (Bioreaktor dengan komposisi kompos:pasir = 1:3 untuk ukuran mesh 8/14).

Dari hasil tersebut maka semakin permeabilitas, maka harga $\mathrm{k}_{\mathrm{r}}$ semakin besar sehingga parameter $\kappa$ juga meningkat, peningkatan harga $\kappa$ yang signifikan menyebabkan peningkatan pengambilan air oleh akar yang signifikan hingga suatu batas tertentu. Kemungkinan besar ini merupakan salah faktor yang meningkatkan produktivitas tanaman pada saat menggunakan kompos dalam medium tanamnya. Namun jika hanya berdasarkan permeabilitas saja, pasir berbatu dengan harga permeabilitas yang juga jauh diatas $\kappa=2,089$ (pada faktor $10^{3}$ ), terlihat memberikan hasil yang lebih baik dibandingkan dengan tanah biasa, karena memberikan peningkatan tekanan cairan yang signifikan. Namun pada kenyataannya tanaman tidak berkembang dengan baik di medium yang hanya terdiri dari batuan pasir, tentu ada faktor yang juga patut menjadi prtimbangan terhadap peningkatan produksi tanaman selain permeabilitas. Dengan membandingkan hasil ini dengan estimasi distribusi tekanan di bioreaktor maka kondisi K:P 1:3 memberikan pola aliran yang masih dapat ditingkatkan lagi (Gambar 6.) di dalam bioreaktor tanaman hingga kondisi K:P 1:1, sehingga untuk menambah kenyamanan dalam memastikan keberlangsungan aliran maka disimpulkan bahwa K:P 1:1 adalah kondisi yang lebih tepat.

\section{KESIMPULAN}

Pada kajian ini terdapat tiga model aliran yang diajukan masing-masing hanya berbeda dari sisi kompleksitasnya, model pertama memiliki empat parameter memiliki kesalahan sebesar 0,457, sedangkan model kedua memiliki lima parameter dengan kesalahan sebesar 0,464, model terakhir dengan tujuh parameter dengan kesalahan sebesar 0,574, dengan model tersebut diketahui bahwa dengan meningkatnya ukuran porositas dan fraksi kompos maka akan memberikan peningkatan terhadap permeabilitas, dan hal ini bersesuaian dengan keadaan percobaan. Untuk menjamin aliran air di dalam bioreaktor tersebut, disarankan menggunakan kompos sebesar setengah dari volum unggun total. Serta perlu dikaji lagi faktor lain yang juga penting terhadap peningkatan produksi tanaman selain permeabilitas.

\section{DAFTAR PUSTAKA}

Abranches, R., Marcel, S., Arcalis, E., Altmann, F., Fevereiro, P., and Stoger ,E., (2005), Plants as bioreactors: a comparative study suggests that Medicago truncatula is a promising production system, J. Biotechnology, 120, pp.121-134.

Bird, R.B., Stewart, W.E., and Lightfoot, E.N., (2002), Transport Phenomena, $2^{\text {nd }}$ Ed, John Wiley \& Sons, p. 40-190, 197-218.

Bish, M., (1987), Laminar Flow Through Unconsolidated Packed Beds of Spherical and Nonspherical Material, International Journal of Mine Water, 6, pp. 1-24.

Kareem, O.N., (2008), Estimated Equations for Water Flow Through Packed Bed of Mono Size Spherical Packing System, Iraqi Journal of Civil Engineering, 6(3), pp. 60-69.

Marshall, T.J., (1958), A Relation Between Permeability and Size Distribution of Pores, Journal of Soil Science, 9(1), pp.1- 8.

Molz, F.J., (1981), Models of Water Transport in the Soil-Plant System: A Review, Water Resources Research, 17(5), pp. 1245-1252.

Purwasasmita, M. and Sutaryat, A., (2012) Padi SRI Organik Indonesia, Penebar Swadaya, p. 17-18.

Richard, L.A., (1931), Capillary Conduction of Liquids through Porous Mediums, Journal Applied of Physics, 1, pp. 318-333. 
Roose, T., (2000), Mathematical Model of Plant Nutrient Uptake, Doctoral Thesis, Linacre College, University of Oxford.

Sharma, A.K. and Sharma, M.K., (2009), Plants as bioreactor: recent developments and emerging opportunities, Biotechnology Advanves, 27, pp. 811832.
Yu, B. and Cheng, P., (2002), A Fractal Permeability Model For Bi-Dispersed Porous Media, International Journal of Heat and Mass Transfer, 45, pp. 29832993. 